\title{
QUALIDADE PÓS-COLHEITA DE QUATRO CULTIVARES DE PESSEGUEIRO EM TRÊS SAFRAS
}

\author{
Jéssica Laísca Fernanda de Azevedo ${ }^{1 *}$, Bianca da Silva Xavier ${ }^{1}$, Priscila Maria Dias \\ Miranda $^{1}$, Keise Duarte Bacelar de Morais ${ }^{1}$, Danielle Fabíola Pereira da Silva ${ }^{2}$, João Alison \\ Alves Oliveira ${ }^{3}$, Cláudio Horst Bruckner ${ }^{4}$ \\ ${ }^{1}$ Graduandas em Agronomia, - Departamento de Fitotecnia, Setor de Futicultura. Viçosa, Minas Gerais, Brasil. \\ E-mail: jessicalaisca@gmail.com,_bxavier02@gmail.com,_priscilamiranda.ufv@gmail.com, \\ keise.morais@ufv.br \\ ${ }^{2}$ Professora do Programa de Pós-Graduação em Agronomia - Universidade Federal de Goiás - Regional Jataí - \\ Rodovia BR 364, Km 192, Setor Parque Industrial. Jataí, Goiás, Brasil. *E-mail: daniellefpsilva@ gmail.com \\ ${ }^{3}$ Doutorando em Fitotecnia - Universidade Federal de Viçosa - Departamento de Fitotecnia, Setor de \\ Futicultura. Viçosa, Minas Gerais, Brasil. E-mail: joao.alison@yahoo.com.br \\ ${ }^{4}$ Professor - Universidade Federal de Vicosa, - Departamento de Fitotecnia, Setor de Futicultura. Viçosa, \\ Minas Gerais, Brasil. E-mail: bruckner@ufv.br
}

RESUMO: A avaliação da qualidade pós-colheita de frutos de pessegueiro destinados à indústria variam entre safras, essa variação depende, entre outros fatores, das condições metereológicas do local de cultivo. Desta forma, o objetivo deste trabalho foi avaliar a qualidade pós-colheita de frutos de quatro cultivares de pessegueiro durante três safras na região da Zona da Mata Mineira. As cultivares Aldrigui, Cerrito, Olímpia e Rei da Conserva foram enxertadas sobre o porta-enxerto Okinawa no pomar experimental da Universidade Federal de Viçosa, Viçosa-MG em 2008 e avaliadas quanto às características cor da casca $\left(b^{*}\right.$ e $h^{\circ}$ ), cor da polpa $\left(b^{*}\right.$ e $h^{\circ}$ ), Massa do fruto (g) Diâmetro polar (mm), Diâmetro equatorial $(\mathrm{mm})$, Firmeza $(\mathrm{N})$ e Diâmetro sutural $(\mathrm{mm})$, Teor de sólidos solúveis $\left({ }^{\mathrm{o} B r i x}\right)$, Vitamina C (mg/100g), Acidez titulável (\% de ácido málico), Carotenoides (mg/100g) e Ratio (relação teor de sólidos solúveis e acidez titulável). O experimento foi conduzido durante safras de 2011, 2012 e 2013, em delineamento inteiramente casualizado, com quatro tratamentos, três repetições e 10 frutos por parcela. Houve diferenças entre as características avaliadas nas três safras para as quatro cultivares. A cultivar Olímpia apresentou os melhores valores de coloração de casca e polpa, e maiores valores de peso e diâmetro de frutos. Os frutos da cultivar Cerrito apresentaram maiores valores de firmeza. As cultivares Olímpia e Cerrito apresetaram no geral maiores valores de sólidos solúveis e acidez. Maiores teores de vitamanina $\mathrm{C}$ foram encontrados nos frutos da cultivar Rei da conserva,e maiores valores de ratio e carotenoides na cultivar Aldrigui.

Palavras-chave: Prunus pérsica. Indústria. Zona da Mata Mineira.

\section{POSTHARVEST QUALITY FOUR PEACH CULTIVARS AT THREE HARVESTS}

ABSTRACT: The evaluation of the peach fruit's postharvest quality for the industry vary between crops.This variation depends, among other factors, of the weather conditions of the cultivation place. Thus, the objective of this study was to evaluate the fruit's post harvest 
quality of four peach varieties for three crops in the area of the Zone Mata Mineira, in the region of Minas Gerais state. The cultivars Aldrigui, Cerrito, Olympia and King of Conserves were grafted on rootstock Okinawa in the experimental orchard of the Federal University of Viçosa (Campus located in Viçosa-MG), in 2008 and evaluated for skin color characteristics $\left(\mathrm{b} * \mathrm{~h}^{\circ}\right)$, color pulp $\left(\mathrm{b} *\right.$ and $\left.\mathrm{h}{ }^{\circ}\right)$, fruit weight $(\mathrm{g})$ polar diameter $(\mathrm{mm})$, equatorial diameter $(\mathrm{mm})$, firmness $(\mathrm{N})$ and sutural diameter $(\mathrm{mm})$, soluble solids content ( ${ }^{\circ}$ Brix), Vitamin C (mg / 100g), titratable acidity (\% malic acid), Carotenoids (mg / 100g) and ratio (ratio soluble solids and titratable acidity). The experiment was conducted during 2011, 2012 and 2013 crops, in a completely randomized design with four treatments, three repetitions and 10 fruits per plot. There were differences between the characteristics evaluated in three crops for the four cultivars. The Olympia Cultivar had the best values of color and pulp, and higher values of weight and fruits diameter. The fruits from Cerrito cultivar showed higher firmness values. The Olympia and Cerrito cultivars had higher soluble solids and acidity values. Higher vitamanin $\mathrm{C}$ levels were found in king preserve cultivar's fruits, and higher ratio and carotenoid values were found in Aldrigui cultivar.

Key words: Prunus persica. Industry. Mata Mineira Zone.

\section{INTRODUÇÃO}

O avanço na fronteira de produção do pessegueiro, para regiões de clima subtropical e de inverno ameno, deve-se principalmente ao lançamento de novas cultivares, menos exigentes em frio hibernal e à criação de novas tecnologias que possibilitem o desenvolvimento da cultura (LEONEL et al., 2011).

O Brasil produziu na safra 2013, 217.706 toneladas, sendo o Rio Grande do Sul o maior produtor nacional, com 136.841 toneladas. Em Minas Gerais, a cultura encontra-se em desenvolvimento, concentrando sua produção principalmente na zona sul do Estado, pelas características edafoclimáticas desejáveis dessa região (SOUZA et al., 2009). Segundo dados do IBGE (2015) a produção do estado de Minas Gerais em 2015 foi de 20.139 toneladas, sendo o quarto maior produtor, porém, com a maior produtividade $\left(22,55\right.$ t.ha $\left.{ }^{-1}\right)$.

O mercado mundial de frutas dispõe de grande variedade de produtos, o que, juntamente com fatores socioeconômicos, faz com que o consumidor exija boa qualidade e também defina os padrões da mesma.

Nesse sentido, variedades de pêssego selecionadas para conusmo in natura devem seguir padrões específicos, diferentes daqueles exigidos pelos frutos para uso na indústria. Algumas dessas características específicas para uso na indústria são, polpa firme, uniforme, não fundente, aderente ao caroço, sempre amarela e ácida, teores aquequados de sólidos solúveis, tamanhos grandes e diâmetros específicos. De acordo Silva et al. (2016) quanto menos danificado e maior o fruto, maior seu rendimento de polpa ou seja a relação custo de processamento e tamanho da fruta é positiva e significativa. Variedades usadas para indústria como Cerrito e Turmalina, por exemplo, apresentam peso superior a $100 \mathrm{~g}$. Neste contexto, observa-se a importância de avaliações químicas e físicas de frutos em diferentes

Cultura Agronômica, Ilha Solteira, v.25, n.3, p.329-338, 2016 
cultivares como forma de identificar aquelas que são mais indicadas para uso industrialização.

O objetivo deste trabalho foi comparar a qualidade pós-colheita de quatro cultivares de pessegueiro para indústria durante três safras em Viçosa-MG.

\section{MATERIAL E MÉTODOS}

Os trabalhos foram conduzidos com pessegueiro (Prunus persica L. Batsch), no pomar experimental da Universidade Federal de Viçosa (UFV), Viçosa-MG (2045'S e $42^{\circ} 51^{\prime} \mathrm{O}$; $649 \mathrm{~m}$ de altitude), durante as safras de 2011, 2012 e 2013, com quatro cultivares de pessegueiro ('Aldrigui', 'Cerrito', 'Olímpia' e 'Rei da Conserva').

Após um ano de obtenção das mudas, quando estas apresentavam entre $25-30 \mathrm{~cm}$ de altura, elas foram enxertadas sobre o porta-enxerto 'Okinawa', sendo o plantio realizado em outubro de 2008, no espaçamento de 5,0 m entre linhas e 3,5 m entre plantas (572 plantas/ha), em área experimental de 0,2 ha. As plantas foram conduzidas em formato de taça.

A precipitação anual foi de 1322, 1362 e 1400 mm, em 2011, 2012 e 2013, respectivamente, sendo dezembro e janeiro os meses mais chuvosos e julho o mais seco. A temperatura máxima média no mês mais quente foi de $30,9^{\circ} \mathrm{C}$, em fevereiro de 2011 , e no mês mais frio, a temperatura mínima média foi de $9,9{ }^{\circ} \mathrm{C}$, em julho de $2011^{1}$.

Durante a condução do experimento, foram realizadas práticas culturais e fitossanitárias, seguindo-se as recomendações técnicas da cultura. Foi utilizada cianamida hidrogenada, na dosagem de $0,8 \%$ e de $1 \%$ de óleo mineral, para a quebra de dormência das gemas. A solução foi aplicada na segunda semana de junho dos anos de 2011, 2012 e 2013, no estádio de gemas dormentes, por meio de pulverização. Realizaram-se podas de frutificação nos meses de maio e junho de cada safra e o raleio dos frutos foi realizado duas semanas após a plena floração.

Os frutos foram colhidos usando como critério a mudança da coloração de fundo de verde para amarelo-claro ou branco-creme. Após a colheita, os frutos foram armazenados em caixas plásticas com apenas uma camada de fruto e enviados para o Laboratório de Análises de frutas, aproximadamente $2 \mathrm{~km}$ do Pomar Experimental. No laboratório os frutos foram avaliados quanto às características químicas e físicas descritas a seguir: Massa do fruto (MF), em gramas ( $\mathrm{g}$ ), foi obtida com o auxílio de balança digital com precisão de 0,1 g. Os diâmetros polar, equatorial e sutural foram obtidos com auxílio de paquímetro digital e os dados expressos em (mm).

A cor da epiderme (medida na região equatorial em lados opostos do fruto) foi dada pela coordenada $b^{*}$ e ângulo Hue $\left(h^{\circ}\right)$, determinados por reflectometria, utilizando-se reflectômetro Minolta (Color Reader CR- 10) (MCGUIRRE, 1992).

${ }^{1}$ Fonte: Estação Meteorológica da Universidade Federal de Viçosa, Viçosa-MG

Cultura Agronômica, Ilha Solteira, v.25, n.3, p.329-338, 2016 
A firmeza da polpa $(\mathrm{N})$ foi determinada na região equatorial de uma das faces do fruto, após a remoção da epiderme, através de penetrômetro digital com ponteira de $8 \mathrm{~mm}$ de diâmetro.

O teor de sólidos solúveis (SS), expresso em (\%), foi analisado no suco retirado manualmente do fruto, por meio de refratômetro digital.

A acidez titulável (AT) foi obtida por titulação com solução de $\mathrm{NaOH} 0,1 \mathrm{~N}$, expressando-se o resultado em percentagem de ácido málico.

O teor de ácido ascórbico (Vitamina C) foi determinada por titulação com reagente de Tillmans [2,6 diclorofenolindofenol (sal sódico) a 0,1\%] e os resultados expressos em mg de ácido ascórbico por $100 \mathrm{~g}$ de polpa.

Os carotenoides totais (CT) foram obtidos pelas equações de Lichtenthaler (1987), em $\mu \mathrm{g} . \mathrm{mL}^{-1}$ de extrato, a partir de leituras em espectrofotômetro nos comprimentos de onda de $470,646,8$ e $663,2 \eta \mathrm{m}$. Os resultados foram multiplicados por 25 e divididos pela massa de polpa, sendo expressos em mg. $100 \mathrm{~g}^{-1}$ de polpa.

Foi utilizado delineamento inteiramente casualizado, com quatro tratamentos (cultivares), três repetições e dez frutos por parcela, avaliados nas safras de 2011, 2012 e 2013. Os dados obtidos foram submetidos à análise de variância individual e conjunta, e as médias comparadas pelo teste Tukey ao nível de 5\% de probabilidade. Foi calculado também o coeficiente de repetibildade. As análises foram realizadas com o auxílio do aplicativo computacional em estatística aplicado à genética - GENES (CRUZ, 2016).

\section{RESULTADOS E DISCUSSÃO}

$\mathrm{Na}$ análise conjunta dos dados, observou-se que as características que não apresentaram diferença significativa entre as cultivares pelo teste $F$ foram $h^{0}$ casca, $b^{*}$ polpa e $\mathrm{h}^{0}$ polpa (Tabela 1). Avaliando-se as safras, as únicas características que não apresentaram diferença significativa foram $b^{*}$ casca e $h^{0}$ polpa. A interação cultivar $x$ safras foi significativa para todas as características avaliadas; sendo assim, optou-se pela aplicação do teste de comparação de médias para comparar cultivares dentro de cada safra.

A coloração da polpa e da epiderme dos frutos são uns dos principais parâmetros de qualidade do pêssego. Na safra de 2011 observa-se que a cultivar Olímpia se destacou para a coordenada $b^{*}$ de cor da casca nas safras de 2011 e 2012 (Tabelas 2 e 3). Para a safra de 2013 as cultivares Olímpia e Rei da conserva não diferiram estatistiscamente entre si (Tabela 4) e apresentaram melhor coloração das casca em relação a coordenada b* da casca, o que indica coloração de epiderme com amarelo mais intenso.

Para coloração da polpa nas safras 2011 e 2012 a cultivar Olimpia apresentou coloração de amarelo mais intenso, diferindo estatisticamente das demais cultivares em estudo (Tabelas 2 e 3). Para a safra de 2013 as cultivares Cerrito e Olímpia apresentaram as melhores colorações de polpa, não diferindo estatisticamente entre si (Tabela 4). Melhores médias indicam que os frutos da cultivar Olímpia apresetam melhor coloração de polpa para 
indústria, ou seja, os frutos dessa variedade apresentam a polpa amarelo mais intenso. Os menores valores de coloração de casca e polpa foram observados nas cultivares Aldrigui e Cerrito. Devido estas cultivares apresentarem polpa com amarelo mais claro, o seu uso na indústria pode requerer o aditivo de corantes, o que pode elevar os custos com o processamento.

Tabela 1. Análise de variância conjunta de cor da casca $\left(b^{*} e^{\circ}\right)$, cor da polpa $\left(b^{*}\right.$ e $\left.h^{\circ}\right)$, Massa do fruto (g) Diâmetro polar (mm), Diâmetro equatorial (mm), Firmeza (N) e Diâmetro sutural (mm), Teor de sólidos solúveis ( ${ }^{\circ}$ Brix), Vitamina C (mg/100g), Acidez titulável (\% de ácido málico), Carotenoides $(\mathrm{mg} / 100 \mathrm{~g}$ ) e Ratio (relação teor de sólidos solúveis e acidez titulável).de quatro cultivares de pessegueiro destinadas para indústria nas safras de 2011, 2012 e 2013

\begin{tabular}{|c|c|c|c|c|c|c|c|c|}
\hline \multirow[t]{2}{*}{$\mathrm{FV}$} & \multicolumn{8}{|c|}{ Quadrado médio } \\
\hline & GL & $b^{*} \mathrm{c}$ & $\mathrm{h}^{\circ} \mathrm{c}$ & $b^{*} p$ & $\mathrm{~h}^{\circ} \mathrm{p}$ & $\mathrm{MF}$ & $\mathrm{DP}$ & $\mathrm{DE}$ \\
\hline $\mathrm{C}$ & 3 & $26,05 *$ & $86,0^{\text {ns }}$ & $36,1^{\mathrm{ns}}$ & $90,9^{\text {ns }}$ & $2880,1 *$ & $233,4 * *$ & $141,6^{*}$ \\
\hline $\mathrm{S}$ & 2 & $0,72^{\mathrm{ns}}$ & $89,1 * *$ & $5,38^{*}$ & $6,49^{\text {ns }}$ & $881,9 * *$ & $35,3 * *$ & $40,01 * *$ \\
\hline $\mathrm{CxS}$ & 6 & $2,99 * *$ & $51,9 * *$ & $34,2 * *$ & $35,2 * *$ & $369,9 * *$ & $12,8 * *$ & $19,1 * *$ \\
\hline $\mathrm{R}$ & 24 & 0,65 & 4,67 & 1,32 & 3,83 & 27,1 & 2,4 & 1,2 \\
\hline $\mathrm{T}$ & $\begin{array}{l}3 \\
5\end{array}$ & & & & & & & \\
\hline $\mathrm{CV}$ & & 2,6 & 2,3 & 3,2 & 2,6 & 5,7 & 2,5 & 2,2 \\
\hline \multirow[t]{2}{*}{$\mathrm{FV}$} & \multicolumn{8}{|c|}{ Quadrado médio } \\
\hline & GL & $\mathrm{DS}$ & FIR & TSS & $\mathrm{VC}$ & AT & $\mathrm{CR}$ & RT \\
\hline $\mathrm{C}$ & 3 & $144,9 *$ & $873,8^{*}$ & $1,87 \mathrm{~ns}$ & $4,69 \mathrm{~ns}$ & $0,197 *$ & $0,312 *$ & $113,2^{*}$ \\
\hline S & 2 & $57,5^{* *}$ & $189,6 * *$ & $1,21 * *$ & $189,1 * *$ & $0,025 * *$ & $0,06^{*}$ & $21,01 * *$ \\
\hline $\mathrm{CxS}$ & 6 & $17,7 * *$ & $158,6 * *$ & $2,73 * *$ & $3,18 * *$ & $0,023 * *$ & $0,06 * *$ & $11,8 * *$ \\
\hline $\mathrm{R}$ & 24 & 1,86 & 30,2 & 0,188 & 0,58 & 0,002 & 0,012 & 1,8 \\
\hline $\mathrm{T}$ & $\begin{array}{l}3 \\
5\end{array}$ & & & & & & & \\
\hline $\mathrm{CV}$ & & 2,5 & 12,8 & 3,7 & 7,1 & 7,5 & 10,6 & 7,0 \\
\hline
\end{tabular}

*significativo ao nível de $5 \%$ de probabilidade pelo teste $\mathrm{F}$, **significativo ao nível de $1 \%$ de probabilidade pelo teste $\mathrm{F}$ e ${ }^{\mathrm{ns}}$ não significativo.

Para massa fresca do fruto a cultivar Olímpia obteve maior peso $(108,1 \mathrm{~g})$ na safra de 2011 (Tabela 2). Na safra de 2012 pêssegos com maior peso foram obtidos nas cultivares Cerrito e Olímpia, não difereindo estatisticamente entre si (Tabela 3). Na safra de 2013 frutos com maior massa fresca foram obtidos pelas cultivares Olímpia, Cerrito e Rei da Conserva (Tabela 4). Resultados semelhantes foram encontrados por Matias et al. (2014). Para Santos et al. (2015), a massa do fruto é uma característica importante, sendo que, em geral, os frutos de maior massa são também os de maior tamanho, e estes, por sua vez, são mais atrativos para indústria.

Para a variável diâmetro médio de frutos, de acordo com as tabelas 2,3 e 4, a cultivar Aldrigui apresentou as maiores valores de diâmetro polar na safra de 2011, enquanto que na

Cultura Agronômica, Ilha Solteira, v.25, n.3, p.329-338, 2016 
safra de 2012 'Cerrito' e 'Olímpia' não diferiram estatisticamente entre si em relação as médias de diâmetro polar.

Tabela 2. Dados médios de cor da casca $\left(b^{*} \mathrm{e}^{\circ}\right)$, cor da polpa $\left(b^{*} \mathrm{e} \mathrm{h}^{\circ}\right)$, Massa do fruto (g) Diâmetro polar (mm), Diâmetro equatorial $(\mathrm{mm})$, Firmeza $(\mathrm{N})$ e Diâmetro sutural $(\mathrm{mm})$, Teor de sólidos solúveis $\left({ }^{\circ}\right.$ Brix), Vitamina C (mg/100g), Acidez titulável (\% de ácido málico), Carotenoides (mg/100g) e Ratio (relação teor de sólidos solúveis e acidez titulável) de quatro cultivares de pessegueiro destinadas para indústria na safra de 2011.

\begin{tabular}{ccccc}
\hline Características avaliadas & \multicolumn{3}{c}{ Cultivares $^{1}$} \\
& 'Aldrigui' & 'Cerrito' & 'Olímpia' & 'Rei da Conserva' \\
\hline Cor da casca $\left(\mathrm{b}^{*}\right)$ & $29,8 \mathrm{~b}$ & $30,2 \mathrm{~b}$ & $32,8 \mathrm{a}$ & $29,9 \mathrm{~b}$ \\
Cor da casca $\left(\mathrm{h}^{\circ}\right)$ & $94,9 \mathrm{a}$ & $96,3 \mathrm{a}$ & $96,4 \mathrm{a}$ & $95,4^{\mathrm{a}}$ \\
Cor da polpa $\left(\mathrm{b}^{*}\right)$ & $35,5 \mathrm{ab}$ & $33,9 \mathrm{~b}$ & $36,1 \mathrm{a}$ & $35,9 \mathrm{ab}$ \\
Cor da polpa $\left(\mathrm{h}^{\circ}\right)$ & $71,8 \mathrm{~b}$ & $74,7 \mathrm{~b}$ & $80,9 \mathrm{a}$ & $72,8 \mathrm{~b}$ \\
Massa do fruto & $77,4 \mathrm{~b}$ & $90,5 \mathrm{ab}$ & $99,5 \mathrm{a}$ & $85,5 \mathrm{ab}$ \\
Diâmetro polar & $54,0 \mathrm{~b}$ & $61,5 \mathrm{a}$ & $62,1 \mathrm{a}$ & $59,9 \mathrm{a}$ \\
Diâmetro equatorial & $51,1 \mathrm{~b}$ & $53,0 \mathrm{~b}$ & $56,9 \mathrm{a}$ & $53,4 \mathrm{~b}$ \\
Diâmetro sutural & $51,9 \mathrm{a}$ & $55,5 \mathrm{a}$ & $56,1 \mathrm{a}$ & $53,27 \mathrm{a}$ \\
Firmeza & $44,1 \mathrm{ab}$ & $57,2 \mathrm{a}$ & $44,2 \mathrm{ab}$ & $36,2 \mathrm{~b}$ \\
Teor de sólidos solúveis & $11,5 \mathrm{~b}$ & $11,9 \mathrm{~b}$ & $11,5 \mathrm{~b}$ & $13,1^{\mathrm{a}}$ \\
Vitamina C & $7,57 \mathrm{~b}$ & $9,98 \mathrm{a}$ & $9,80 \mathrm{a}$ & $9,60 \mathrm{ab}$ \\
Acidez titulável & $0,72 \mathrm{~b}$ & $0,86 \mathrm{a}$ & $0,60 \mathrm{c}$ & $0,66 \mathrm{bc}$ \\
Carotenoides & $1,4 \mathrm{a}$ & $0,98 \mathrm{~b}$ & $0,68 \mathrm{c}$ & $1,26 \mathrm{a}$ \\
Ratio & $16,3 \mathrm{~b}$ & $14,2 \mathrm{c}$ & $19,4 \mathrm{a}$ & $20,1 \mathrm{a}$ \\
\hline
\end{tabular}

1 médias seguidas pela mesma letra nas linhas não diferem entre si pelo teste de Tukey ao nível de 5\% de probabilidade.

Matias et al. (2014), ao comparar treze variedades de pêssego, dentre elas Aldrigui, Cerrito e Olímpia também observaram maiores valores de diâmetros para as cultivares Olímpia e Cerrito, com valores próximos aos mensurados neste trabalho. O menor valor de diâmetro foi observada na cultivar Aldrigui. De acordo com Silva et al. (2016), quanto maior a fruta, maior é seu rendimento em polpa, menores os gastos de mão de obra, e em equipamentos industriais, melhor a aparência da compota e portanto, maior seu valor comercial. Desta forma avaliando este parâmetro as cultivares Olímpia e Cerrito seriam as mais inidicadas para uso na indústria.

A cultivar Cerrito apresentou a maior de firmeza de polpa na safra de 2011 (Tabela 2), resultado que se opõem a outros encontrados em estudos anteriores, que relacionam maior firmeza de frutos a frutos de pessegueiro com menor diâmetro. Na safra de 2013 as cultivares Aldrigui e Cerrito aprsentaram maior firmeza 52,3 e 51,5N, respectivamente (Tabela 4). De acordo com do Wagner Júnior et al. (2011) a firmeza da polpa do fruto está relacionada a sua resistência ao transporte, consequentemente frutos mais firmes apresentam melhor potencial pós-colheita. Dessa forma, a firmeza da polpa é um requisto fundamental para que os frutos sejam ultilizados na indústria. 
As características físicas e químicas demonstradas pelos teores de sólidos solúveis, acidez titulável e açúcares, entre outras, são indicadoras das características sensoriais, importantes para o consumo in natura e também para a indústria (CHITARRA; CHITARRA, 2005).

Tabela 3. Dados médios de cor da casca $\left(b^{*}\right.$ e $\left.h^{\circ}\right)$, cor da polpa $\left(b^{*}\right.$ e $\left.h^{\circ}\right)$, Massa do fruto (g) Diâmetro polar (mm), Diâmetro equatorial (mm), Firmeza $(\mathrm{N})$ e Diâmetro sutural $(\mathrm{mm})$, Teor de sólidos solúveis ( ${ }^{\circ}$ Brix), Vitamina C (mg/100g), Acidez titulável (\% de ácido málico), Carotenoides (mg/100g) e Ratio (relação teor de sólidos solúveis e acidez titulável) de quatro cultivares de pessegueiro destinadas para indústria na safra de 2012.

\begin{tabular}{lllll}
\hline Características avaliadas & \multicolumn{3}{c}{ Cultivares' } \\
& 'Aldrigui' & 'Cerrito' & 'Olímpia' & 'Rei da Conserva' \\
\hline Cor da casca $\left(\mathrm{b}^{*}\right)$ & $28,9 \mathrm{~b}$ & $29,7 \mathrm{~b}$ & $32,9 \mathrm{a}$ & $30,5 \mathrm{~b}$ \\
Cor da casca $\left(\mathrm{h}^{\circ}\right)$ & $87,9 \mathrm{~b}$ & $96,6 \mathrm{a}$ & $87,2 \mathrm{~b}$ & $90,4 \mathrm{ab}$ \\
Cor da polpa $\left(\mathrm{b}^{*}\right)$ & $34,7 \mathrm{~b}$ & $30,3 \mathrm{c}$ & $39,9 \mathrm{a}$ & $35,8 \mathrm{~b}$ \\
Cor da polpa $\left(\mathrm{h}^{\circ}\right)$ & $69,3 \mathrm{~b}$ & $70,8 \mathrm{~b}$ & $80,3 \mathrm{a}$ & $75,9 \mathrm{ab}$ \\
Massa do fruto & $54,7 \mathrm{c}$ & $102,4 \mathrm{a}$ & $107,9 \mathrm{a}$ & $68,8 \mathrm{~b}$ \\
Diâmetro polar & $49,5 \mathrm{c}$ & $64,7 \mathrm{a}$ & $63,1 \mathrm{a}$ & $54,9 \mathrm{~b}$ \\
Diâmetro equatorial & $44,2 \mathrm{~d}$ & $54,2 \mathrm{~b}$ & $57,6 \mathrm{a}$ & $48,9 \mathrm{~b}$ \\
Diâmetro sutural & $44,2 \mathrm{c}$ & $55,9 \mathrm{~b}$ & $57,8 \mathrm{a}$ & $49,6 \mathrm{~b}$ \\
Firmeza & $41,6 \mathrm{a}$ & $56,1 \mathrm{a}$ & $42,3 \mathrm{a}$ & $40,4 \mathrm{a}$ \\
Teor de sólidos solúveis & $11,3 \mathrm{~b}$ & $11,0 \mathrm{~b}$ & $11,5 \mathrm{ab}$ & $12,3{ }^{\mathrm{a}}$ \\
Vitamina C & $14,3 \mathrm{~b}$ & $13,9 \mathrm{~b}$ & $15,4 \mathrm{ab}$ & $17,1 \mathrm{a}$ \\
Acidez titulável & $0,56 \mathrm{~b}$ & $0,79 \mathrm{a}$ & $0,54 \mathrm{~b}$ & $0,59 \mathrm{~b}$ \\
Carotenoides & $1,22 \mathrm{a}$ & $1,21 \mathrm{a}$ & $0,81 \mathrm{~b}$ & $1,09 \mathrm{ab}$ \\
Ratio & $21,1 \mathrm{a}$ & $14,7 \mathrm{~b}$ & $21,9 \mathrm{a}$ & $21,1 \mathrm{a}$ \\
\hline
\end{tabular}

${ }^{1}$ médias seguidas pela mesma letra nas linhas não diferem entre si pelo teste de Tukey ao nível 5\% de probabilidade.

Os maiores teores de sólidos solúveis foi encontrado na cultivar Rei da conserva na safra de 2011 (Tabela 2). Na safra de 2013 a cultivar Cerrito obteve maior teor de sólidos solúveis $\left(12,9^{\circ}\right.$ Brix $)$, diferindo das demais cultivares em estudo (Tabela 4).

Valores inferiores de sólidos solúveis foram encontrados por Ramos e Leonel (2008), avaliando 12 cultivares de pêssegos na região de Botucatu-SP, que obtiveram frutos com valores de sólidos solúveis entre $8,8^{\circ}$ Brix e $16,3^{\circ}$ Brix. O menor teor de sólidos solúveis foi identificado na cultivar Olímpia, com $11,07^{\circ}$ Brix, esse valor esta relacionado à acidez do fruto, quanto maior acidez menor teor de sólidos solúveis (RAMOS; LEONEL, 2008). Embora esses valores de sólidos solúveis sejam considerados baixos para frutos destinados ao consumo in natura, frutos para uso na indústria podem ter acidez mais elevada e consequentemente menor teor de sólidos solúveis. De acordo com Gonçalves et al. (2014), uma mesma cultivar, sofre efeito de vários fatores, entre eles, o estádio de maturação, as condições climáticas, e a localização do fruto na planta.

Maior teor de acidez titulável foi obtida pela cultivar Cerrito em todas as safras em avaliadas (Tabelas 2, 3 e 4), com valor médio de 0,86\% de ácido málico. Em estudo Cultura Agronômica, Ilha Solteira, v.25, n.3, p.329-338, 2016 
semelhante feito por Matias et al. (2014), foram encontrados teores relativamente parecidos $0,6 \%$ e $0,86 \%$ respectivamente.

Tabela 4. Dados médios de cor da casca $\left(b^{*}\right.$ e $\left.h^{\circ}\right)$, cor da polpa $\left(b^{*}\right.$ e $\left.h^{\circ}\right)$, Massa do fruto (g) Diâmetro polar (mm), Diâmetro equatorial $(\mathrm{mm})$, Firmeza $(\mathrm{N})$ e Diâmetro sutural $(\mathrm{mm})$, Teor de sólidos solúveis ( ${ }^{\circ}$ Brix), Vitamina C (mg/100g), Acidez titulável (\% de ácido málico), Carotenoides $(\mathrm{mg} / 100 \mathrm{~g})$ e Ratio (relação teor de sólidos solúveis e acidez titulável).de quatro cultivares de pessegueiro destinadas para indústria na safra de 2013.

\begin{tabular}{lllll}
\hline Características avaliadas & \multicolumn{4}{c}{ Cultivares } \\
& 'Aldrigui' & 'Cerrito' & 'Olímpia' & 'Rei da Conserva' \\
\hline Cor da casca $\left(\mathrm{b}^{*}\right)$ & $29,4 \mathrm{~b}$ & $28,6 \mathrm{~b}$ & $33,2 \mathrm{a}$ & $32,8 \mathrm{a}$ \\
Cor da casca $\left(\mathrm{h}^{\circ}\right)$ & $97,2 \mathrm{a}$ & $97,4 \mathrm{a}$ & $88,5 \mathrm{~b}$ & $83,9 \mathrm{~b}$ \\
Cor da polpa $\left(\mathrm{b}^{*}\right)$ & $27,9 \mathrm{~b}$ & $37,6 \mathrm{a}$ & $35,9 \mathrm{a}$ & $35,0 \mathrm{a}$ \\
Cor da polpa $\left(\mathrm{h}^{\circ}\right)$ & $75,3 \mathrm{~b}$ & $79,1 \mathrm{a}$ & $76,8 \mathrm{ab}$ & $70,9 \mathrm{c}$ \\
Massa do fruto & $68,8 \mathrm{~b}$ & $106,7 \mathrm{a}$ & $116,9 \mathrm{a}$ & $107,9 \mathrm{a}$ \\
Diâmetro polar & $55,2 \mathrm{c}$ & $65,6 \mathrm{a}$ & $64,5 \mathrm{ab}$ & $60,6 \mathrm{~b}$ \\
Diâmetro equatorial & $48,6 \mathrm{c}$ & $54,8 \mathrm{~b}$ & $58,2 \mathrm{a}$ & $57,6 \mathrm{a}$ \\
Diâmetro sutural & $50,0 \mathrm{~b}$ & $58,1 \mathrm{a}$ & $59,4 \mathrm{a}$ & $57,5 \mathrm{a}$ \\
Firmeza & $52,3 \mathrm{a}$ & $51,5 \mathrm{a}$ & $30,6 \mathrm{~b}$ & $19,1 \mathrm{c}$ \\
Teor de sólidos solúveis & $11,9 \mathrm{ab}$ & $12,9 \mathrm{a}$ & $10,1 \mathrm{c}$ & $10, \mathrm{bc}$ \\
Vitamina C & $7,09 \mathrm{a}$ & $8,36 \mathrm{a}$ & $7,98 \mathrm{a}$ & $7,14 \mathrm{a}$ \\
Acidez titulável & $0,76 \mathrm{~b}$ & $0,93 \mathrm{a}$ & $0,44 \mathrm{c}$ & $0,47 \mathrm{c}$ \\
Carotenoides & $1,09 \mathrm{a}$ & $0,94 \mathrm{a}$ & $0,87 \mathrm{a}$ & $0,94 \mathrm{a}$ \\
Ratio & $16,2 \mathrm{~b}$ & $14,7 \mathrm{~b}$ & $24,6 \mathrm{a}$ & $23,9 \mathrm{a}$ \\
\hline
\end{tabular}

${ }^{1}$ médias seguidas pela mesma letra nas linhas não diferem entre si pelo teste de Tukey a 5\% de probabilidade.

Maiores valores de ratio foram encontrados para as cultivares Olímpia e Rei da Conserva nas safras 2011 e 2013 (Tabelas 2 e 4). Na safra de 2012, maior relação do teor de sólidos solúveis e acidez titulável foram registados para 'Aldrigui'e 'Olímpia'. Os menores valores de ratio foram observados na cultivar Cerrito com média de 14,53 nas três safras em estudo. Resultados semelhantes foram encontrados por Matias et al (2014), que relaciona os altos valores de ratio principalmente à baixa acidez dos frutos, que coincide com que ocorreu neste trabalho. As duas cultivares Olimpia e Rei da conserva com maiores valores de ratio, obtiveram os menores valores de acidez.

De acordo com a tabela 2, os maiores teores de vitamina $\mathrm{C}$ foram obtidos para 'Cerrito'e 'Olímpia'na safra de 2011. Na safra de 2012 a cultivar Rei da conserva apresentou maior teor de vitamina $\mathrm{C}(17,1 \mathrm{mg} / 100 \mathrm{~g})$, no entanto, diferindo estatiscamente das cultivares em estudo. $\mathrm{O}$ menor valor de vitamina $\mathrm{C}$ foi obtido em frutos da cultivar Aldrigui (7,09mg/100g) na safra 2013. Matias et al. (2014), ao comparar treze cultivares de pêssego também encontrou menores teores de vitamina $\mathrm{C}$ na cultivar Aldrigui $(7,58 \mathrm{mg} / 100 \mathrm{~g})$. Segundo alguns autores, em frutas, os teores de vitamina $\mathrm{C}$ podem variar de acordo com local de cultivo e manejo da cultura. Maior teor de vitamina $\mathrm{C}$ é uma caracteristica desejada tanto para consumo dos frutos in natura quanto para uso dos frutos na indústria.

Cultura Agronômica, Ilha Solteira, v.25, n.3, p.329-338, 2016 
Os maiores valores de carotenoides foram obtidos nos frutos da cultivar Aldrigui $(1,4 \mathrm{mg} / 100 \mathrm{~g})$ na safra de 2011, valor superior ao observado por Segantini et al. (2012). Os menores valores foram obtidos nos frutos da cultivar Olímpia $(0,68 \mathrm{mg} / 100 \mathrm{~g})$ na safra de 2011. Valores próximos foram observados por Matias et al. (2014), (1,40mg/100g) e $(0,69 \mathrm{mg} / 100 \mathrm{~g})$, respectivamente. De acordo com Faraoni et al. (2008) a coloração amarela do fruto esta estritamente ligada aos pigmentos caratonoides, sendo esta uma característica essencial para que o fruto possa ser usado na indústria. Com base nesta característica de forma especifica a cultivar Aldrigui seria a mais recomendada.

\section{CONCLUSÃO}

A cultivar Olímpia apresenta os melhores valores de coloração de epiderme e polpa, e maiores valores de diâmetro e massa de fruto.

A cultivar Cerrito apresenta frutos com maiores valores de firmeza. As cultivares Rei da Conserva e Cerrito apresetam no geral maiores valores de sólidos solúveis e acidez.

As cultivares Cerrito, Olímpia e Rei da conserva apresentam frutos com maiores teores de vitamanina $\mathrm{C}$.

A cultivar Aldrigui apresenta frutos com maior teor de carotenoides.

\section{AGRADECIMENTOS}

Ao CNPq, CAPES e FAPEMIG pelo apoio financeiro.

\section{REFERÊNCIAS BIBLIOGRÁFICAS}

CHITARRA, M. I. F.; CHITARRA, A. B. Pós-colheita de frutas e hortaliças: fisiologia e manuseio. Lavras: UFLA, 2005. 785 p.

CRUZ, C. D. Genes Software - extended and integrated with the R, Matlab and Selegen. Acta Scientiarum, Maringá, v. 38, n. 4, p. 547-552, 2016.

FARAONI, A. S.; RAMOS, A. M.; STRINGHETA, P. C.; LAUREANO, J. Efeito dos métodos de conservação, tipos de embalageme tempo de estocagem na coloração de polpa de manga "Ubá" produzida em sistema orgânico. Revista Ceres, Viçosa, v. 55, n. 6, p. 504$511,2008$.

GONCAlveS, M. A., PICOlOtTO, L.; AZEVEDO, F. Q.; COCCO, C.; ANTUNES, L. E. C. Qualidade de fruto e produtividade de pessegueiros submetidos a diferentes épocas de poda. Ciência Rural, Santa Maria, v. 44, n. 8, p.1334-13040, 2014.

IBGE - Instituto Brasileiro de Geografia e Estatística. Produção Agrícola Municipal. 2015. Disponível em: http://www.sidra.ibge.gov.br . Acesso em: 04 jun. 2016.

Cultura Agronômica, Ilha Solteira, v.25, n.3, p.329-338, 2016 
LEONEL, S.; PIEROZZI, C. G.; TECCHIO, M. A. Produção e qualidade dos frutos de pessegueiro e nectarina em clima subtropical do estado de São Paulo. Revista Brasileira de Fruticultura, Jaboticabal, v. 33, n. 1, p.118-128, 2011.

LICHTENTHALER, H. K. Chlorophylls and carotenoids: Pigments of photosynthetic biomembranes. Methods in Enzymology, Amsterdam, v. 148, p.349-382, 1987.

MATIAS, R. G. P.; SILVA, D. F. P.; RIBEIRO, M. R.; SILVA, J. O. C. E; OLIVEIRA, S. P.; BRUCKNER, C. H. Características de frutos de pessegueiros cultivados na Zona da Mata de Minas Gerais. Ciência Rural, Santa Maria, v. 44, n. 6, p.971-974, 2014.

MCGUIRE, RG. Reporting of objective color measurements. HortScience, Virginia, v. 2, p.1254-1260, 1992.

RAMOS, D. P.; LEONEL, S. Características dos frutos de cultivares de pessegueiros e de nectarineira, com potencial de cultivo em Botucatu, SP. Bioscience Journal, Uberlândia, v. 24, n. 1, p.10-18, 2008.

SANTOS, J. A.; NASSER, F. A. C. M.; NASSER, M. D. Qualidade dos frutos de goiabeiras submetidas à poda e aplicação de nitrato de potássio. Cultura Agronômica, Ilha Solteira, v. 24, n. 4, p.271-280, 2015.

SIlvA, D. F. P.; MATIAS, R. G. P.; SilvA, J. O. C. E; BRUCKNER, C. H. Characterization of white-fleshed peach cultivars grown in the Zona da Mata area of Minas Gerais State, Brazil. Comunicata Scientiae, Bom Jesus, v. 7, n. 1, p.149-153, 2016.

SEGANTINI, D. M; LEONEL, S.; LIMA, G. P. P; COSTA, S. M; RAMOS, A. R. P. Características da polpa de pêssegos produzidos em São Manuel-SP. Ciência Rural, Santa Maria, v.42, n. 1, p.52-57, 2012.

SOUZA, A. V.; KOHATSU, D. S.; LIMA, G. P. P. E; VIEITES, R. L. Conservação póscolheita de pêssego com o uso da refrigeração e da irradiação. Revista Brasileira de Fruticultura, Jaboticabal, v. 31, n. 4, p.1184-1189, 2009.

WAGNER JÚNIOR, A., BRUCKNER, C. H., CANTÍN, M. C., SÁNCHEZ, M. A. M., SANTOS, C. E. M. Seleção de progênies e genitores de pessegueiro com base nas características dos frutos. Revista Brasileira de Fruticultura, Jaboticabal, v. 33, n. 3, p.170-179, 2011. 